\title{
Delayed initiation of enteral feeds is associated with postnatal growth failure among preterm infants managed at a rural hospital in Uganda
}

Clare Nakubulwa ${ }^{1 *}$ (D), Victor Musiime ${ }^{1}$, Flavia B. Namiiro ${ }^{1}$, James K Tumwine ${ }^{1,2}$, Christine Hongella ${ }^{1}$, James Nyonyintono ${ }^{3}$, Anna B. Hedstrom ${ }^{4}$ and Robert Opoka ${ }^{1}$

\begin{abstract}
Background: Prematurity is the leading cause of mortality in children under 5 years of age globally and is also frequently associated with postnatal growth failure (PGF). Although most preterm births occur in low resource settings, little is known about their postnatal growth outcomes especially in rural areas. We evaluated the incidence and factors associated with PGF among preterm infants managed at a rural hospital in Uganda.

Methods: Retrospective cohort study of preterm infants discharged from Kiwoko Hospital neonatal intensive care unit (NICU) from July 2017 to June 2018. Inclusion criteria included gestational age 26 up to but not including 37 weeks, admission within $24 \mathrm{~h}$ of birth and at least 7 days hospital stay. Exclusion criteria included major congenital anomalies and missing gestational age or birth weight. Birth and discharge weights from clinical notes were plotted on Fenton 2013 growth charts. Gestation age was determined by last normal menstruation period (LNMP), extracted from the mother's antenatal card or early obstetric ultrasound scan reports. Postnatal growth failure was diagnosed if discharge weight was less than the 10th percentile for estimated gestational age. Other data from the clinical notes included demographic characteristics, neonatal morbidities as assigned by the attending physician and infant feeding practices. Multivariable logistic regression was used to explore factors associated with PGF.
\end{abstract}

Results: A total of 349 preterm infants with a mean gestational age of 31 (range 26 to 36) weeks were included. The incidence proportion of PGF was 254/349 (73\%). Factors significantly associated with postnatal growth failure included: delayed initiation of enteral feeds $[\mathrm{AOR}=3.70,95 \%(\mathrm{Cl} 1.64$ to 8.33$)]$, sepsis $[\mathrm{AOR}=$ $6.76,95 \%(\mathrm{Cl} 2.15$ to 21.2)], multiple gestation $[\mathrm{AOR}=1.81,95 \%(\mathrm{Cl} 1.01$ to 3.24$)]$ and male gender $[\mathrm{AOR}=1.71$ $95 \%(\mathrm{Cl} 1.01$ to 2.91$)]$.

Conclusion: Nearly three quarters of preterm infants managed at a rural hospital in Uganda had postnatal growth failure. Delayed initiation of enteral feeds and sepsis were highly associated with postnatal growth failure. Enteral feeds should be initiated as soon as possible in these infants to reduce early protein deficits and hence postnatal growth failure.

Keywords: Postnatal nutrition, Enteral feeds, Growth outcomes, postnatal growth failure

\footnotetext{
* Correspondence: oliviapatie19@gmail.com

${ }^{1}$ Department of Pediatrics and Child Health, School of Medicine, Makerere

University College of Health Sciences, PO Box 7072, Kampala, Uganda

Full list of author information is available at the end of the article
}

(c) The Author(s). 2020 Open Access This article is distributed under the terms of the Creative Commons Attribution 4.0 International License (http://creativecommons.org/licenses/by/4.0/), which permits unrestricted use, distribution, and reproduction in any medium, provided you give appropriate credit to the original author(s) and the source, provide a link to the Creative Commons license, and indicate if changes were made. The Creative Commons Public Domain Dedication waiver (http://creativecommons.org/publicdomain/zero/1.0/) applies to the data made available in this article, unless otherwise stated. 


\section{Background}

Preterm birth is increasing worldwide, with $60 \%$ of these births occurring in middle to low income countries of South Asia and Sub-Saharan Africa. In Uganda, preterm infants make up $14 \%$ of all live births and Uganda ranks at 13th out of 184 countries in rates of preterm births [1]. Preterm infants experience a nutritional emergency as they are suddenly removed from a nutrient rich environment in-utero to the extrauterine life where nutrition is harder to initiate and later on maintain. Although postnatal nutrition in preterm infants is aimed at them attaining growth rates that approximate the intrauterine fetal growth rates [2] growth lags are reported among these hospitalized infants worldwide [3-5]. These growth deficits are not only reflected by poor weight gain but also head circumference and length. Weight below the 10th percentile of the expected intrauterine size of fetuses of the same gestational age is termed as postnatal growth failure (PGF) [3].

Early growth deficits amongst preterm infants results from protein and energy deficits after birth [6] and are associated with poor growth and neurodevelopmental outcomes later in childhood [7, 8]. Even with growing evidence that optimizing nutrition with total parenteral nutrition, early enteral feeds with fast advancement and fortification of human milk improves growth outcomes, resource limited settings have not been able to implement all this because of cost. In Uganda, little has been documented concerning growth outcomes of preterm infants especially in rural areas.

We evaluated the incidence and factors associated with postnatal growth failure amongst preterm infants managed at Kiwoko Hospital- a rural district hospital in central Uganda.

\section{Methods}

\section{Study design}

This was a retrospective cohort study using in-patient records of preterm infants for a 1 year period (July, 2017 to June, 2018).

\section{Study setting}

The study was carried out at Kiwoko Hospital, a rural faith-based hospital in Nakaseke district. The neonatal unit opened in 2001 and is supported by Adara Development an international non-governmental organisation. The unit is well-established and recognised in Uganda as a centre of excellence in newborn care. Services are offered at subsided prices to mainly three rural districts of central Uganda; Nakaseke, Luwero, Nakasongola as well as a few cases from other surrounding districts. With an official bed capacity of 38 , the unit admits over 100 neonates per month, 1200 per year of which prematurity accounts for $40 \%$ of admissions. It is run by a paediatrician supported by one medical officer and a team of nurses. Unit resources include constant electricity, incubators, radiant warmers, intermittent pulse oximetry, phototherapy, intravenous pumps, and continuous positive airway pressure (CPAP). The neonate: nurse ratio per shift is on average $5: 1$.

On admission to the unit, maternal and infant demographic data are recorded on a specified admission sheet by the admitting nurse who also takes anthropometric measurements. Weights are taken using Seca weighing scales with the infants fully undressed. Gestational age is estimated mostly by LNMP from the mother's antenatal card, few by first trimester scan and rarely Ballard score done by the admitting doctor. Further assessement is done by both the admitting and unit doctor who makes a clinical diagnosis and recommends appropriate investigations and treatment.

For all infants, intravenous fluids with $10 \%$ dextrose at $80-100 \mathrm{ml} / \mathrm{kg} /$ day are initiated on admission and electrolytes added on day 3. Each infant is reviewed on a daily basis by the unit doctors and a decisions is made on when to start enteral feeds. Expressed breast milk (EBM) is given initially at $10-20 \mathrm{ml} / \mathrm{kg} /$ day and increased gradually by $10-20 \mathrm{ml} / \mathrm{kg} / \mathrm{d}$ depending on tolerance by the infant as well as the availability of the milk by the mother. Preterm formula is rarely used when mataernal human milk will not be available. There is no donor milk at the facility. For very low birth weight (VLBW) preterm infants feeding is done by nasogastric tube (NGT). More mature and stable infants may feed via cup or at the breast as soon as possible. For breast feeding infants, fluids are stopped once the neonate is breast feeding well and the mother has enough breast milk. For those feeding by cup or nasogastric tube fluids are stopped once the infant can tolerate $15 \mathrm{ml}$ per feed or $150 \mathrm{ml} / \mathrm{kg}$ / day whichever comes first. The mother works closely with the nurses on duty to ensure she gives the prescribed feeds and report any feeds intolerence. This information is recorded in a specified feeds monitoring chart kept in the patients' file and is reviewed daily by the clinician. Neither fortification of human milk nor total parenteral feeding is available at the unit.

Weights are taken on alternate days and feeds are adjusted according to the weight once the neonate starts gaining weight. Supplementation with multivitamins (Grovit drops) and iron (Haemoforte syrup) is started once the neonate is on full enteral feeds. The VLBW and extremely low birth weight (ELBW) infants are discharged once they attain $1.5 \mathrm{~kg}$, with no recorded apneic spells in the past 5 days and have stable vitals in a 
cot. On discharge, their corrected gestation in weeks, discharge weight and head circumference are recorded.

Files of discharged preterm infants are stored in the records department and data on demographics and clinical variables stored electronically for quality improvement use.

\section{Study population}

Neonates with a gestation age between 26 and 36 completed weeks and 6 days (by LNMP, first trimester ultrasound scan or Ballard score) who were admitted to the unit within $24 \mathrm{~h}$ of life and spent 7 or more days in hospital were included into the study. Preterms with major congenital abnormalities and those with missing birth weight or recorded gestation age were excluded from the study. The former were excluded as they were expected to have PGF from other abnormalities.

\section{Study procedure}

Using a structured and pretested data collection tool, we obtained demographic, nutritional and clinical data relevant to the study from patient files that fulfilled the inclusion criteria. This information included: 1) Perinatal factors: Date and time of birth, date of admission, estimated gestational age at birth (LNMP/ early obstetric ultrasound scan/ Ballard score), birth weight, sex, discharge weight. Preterm infants were classified as: extremely preterm $(<28$ weeks), very preterm ( 28 to 32 weeks) and moderate to late preterm $(>32$ to $<37$ weeks) [3].

Maternal characteristics: Age, parity, morbidities like hypertension (HTN) and HIV sero status. 2) Morbidity during hospitalization: Need for CPAP, sepsis or necrotizing enterocolitis (NEC) and oxygen requirement after 28 days. These were diagnoses made by the attending clinician and extracted from patient files.

Definitions of neonatal morbidities in this study were as follows;

Need for CPAP. Preterm infants with a respiratory severity score of 5 and above (using the SilvermanAnderson score) were started on CPAP. Chest X-rays are not routinely performed. CPAP is the treatment modality used for RDS at the unit sincce surfactant and ventilators are not available.

Sepsis: Clinical diagnosis with abnormal axillary temperature $\left(>38.5^{\circ}\right.$ or $<36^{\circ} \mathrm{C}$ ), fast respirations (above 60 breaths per minute) with refusal to breastfeed or new apnoea/ oxygen requirement in one who was previously stable and in the absence of anaemia. Blood cultures are not available.
PDA: A continuous murmur most prominent at the upper left sterna border in a preterm infant with significant cardiovascular compromise (tachycardia, tachypnea).

NEC: Increased gastric residues/ emesis/ bloody stools with abdominal distention, unstable vitals (tempereature, respiration, heart rate) plus or minus abnormal abdominal radiographs.

Apnea: Cessation of breathing for $20 \mathrm{~s}$ or longer, or a shorter respiratory pause associated with bradycardia and desaturations.

Anaemia: Haemoglobin count of $<8 \mathrm{~g} / \mathrm{dL}$ if asymptomatic and off oxygen, $<10 \mathrm{~g} / \mathrm{dL}$ if on oxygen, or $<12 \mathrm{~g} / \mathrm{dL}$ if having apnoeas.

3) Nutrition information: Dates and time of initiating enteral feeds, any documented feeds intolerance (increased gastric residue with or without vomiting of feeds) and date of attaining full enteral feeds. Delayed initiation of enteral feeding in this study was if feeds were started after $48 \mathrm{~h}$ of life.

Birth and discharge weight for each preterm were plotted on Fenton growth charts $2013[9,10]$ and the percentile for each weight read. We used the different charts for boys and girls. We used these charts because they were based on a meta-analysis with the highest number of newborns to date [2]. Birth weight less than the 10th percentile for the estimated gestation age and sex was categorized as small for gestation age (SGA) and that between the 10th and 90th percentile as appropriate for age (AGA). Postnatal growth failure was defined as discharge weight less than the 10th percentile of the expected intrauterine growth for the same postmenstrual age (PMA) and sex [3]. Discharge in this study included those who went home alive as well as those who died after being hospitalized for seven or more days.

\section{Statistical analysis}

Statistical data analysis was done using STATA version 14 (College station, TX). Continuous data were expressed as mean and standard deviation if normally distributed, median and interquartile range if nonnormal. Categorical data were expressed as frequencies and proportions. We used Chi square and Fischer's Exact test to test for presence of association between PGF and the categorical independent variables. The Student's t- test was used for normally distributed continuous variables and Mann-Whitney $U$ test for those with a skewed distribution.

The cumulative incidence of PGF among preterm infants was determined as the number of new cases of PGF out of the total number of infants at risk in the sample. 
We used binary logistic regression to find out the association between the independent variables with PGF. Factors that achieved a $p$-value of less than 0.25 at bivariable analysis and those with biological plausability including gestational age and maternal morbidities (HIV and hypertension) were inserted into a multivariable logistic model. Hosmer-Lemeshow test was used to test the goodness of fit for the model. Adjusted odds ratios and their 95\% confidence intervals were obtained to assess for strength of association and the level of significance was set at $5 \%$.

\section{Results}

A total of 494 preterms were admitted to the unit from July 2017 to June 2018. Of these 130 didn't meet the inclusion criteria and 15 had exclusion criteria. This left a total of 349 preterm infants with a mean gestational age of 31 (range 26 to 36) weeks that were eligible and these were included into the study. The 130 preterm infants who did not meet inclusion criteria included 40 pretems who died within the first week of life, 88 who were discharged before 7 days of life and 2 was was transferred to other units. The 15 preterm infants meeting the exclusion criteria included 5 who had congenital abnormalities, 7 with missing records of gestation age or birth weight, 2 admitted at 2 weeks of age and 1 who was born to a diabetic mother.

\section{Baseline characteristics}

One hundred eighty eight preterm infants were female (53.9\%). Majority were moderate to late preterms 167 (47.9\%) and very preterm 168 (48.1\%). The median length of hospital stay was 14 days (interquatile range $(I Q R)=23)$. Majority of the mothers were aged 20-24 (33\%), 106 (30.5\%) mothers had a parity of one and the prevalence of HIV among the mothers was $8.3 \%$ (Table 1).

The prevalent common morbidity during hospitalization was Respiratory Distress Syndrome (RDS) with 121/349 (34.7\%) requiring CPAP and 47/349 (13.5\%) were managed for sepsis. Enteral feeds were initiated within the first $48 \mathrm{~h}$ in $80.1 \%$ of these preterm infants (Table 2).

In this study $73 \%(254 / 349)$ preterm infants had PGF at discharge (Fig. 1) and the incidence increased with decreasing gestation age as shown in (Fig. 2).

Factors associated with PGF at bivariable analysis are shown in Table 3 and at multivariable analysis, delayed initiation of enteral feeds $[\mathrm{AOR}=3.70,(95 \%$ (CI 1.64 to 8.33)], sepsis $[\mathrm{AOR}=6.76$, (95\% (CI 2.15 to 21.2)], multiple gestation $[\mathrm{AOR}=1.81, \quad(95 \%$ (CI 1.01 to 3.24$)]$ and male gender $[\mathrm{AOR}=1.71(95 \%$ (CI 1.01 to 2.91)] were significant factors. On the contrary, gestational age, maternal age, and HIV status
Table 1 Baseline characteristics of the sample population

\begin{tabular}{|c|c|c|}
\hline \multirow[t]{2}{*}{ Baseline Characteristics } & \multirow[t]{2}{*}{$\begin{array}{l}\text { Median (min- } \\
\max )\end{array}$} & \multirow{2}{*}{$\begin{array}{l}\text { Number(N) } \\
\mathrm{n}(\%) \\
N=349\end{array}$} \\
\hline & & \\
\hline \multicolumn{3}{|l|}{ Infant Characteristics } \\
\hline \multicolumn{3}{|l|}{ Sex of infant } \\
\hline Female & & $188(53.9)$ \\
\hline Male & & $161(46.1)$ \\
\hline \multicolumn{3}{|l|}{ Gestational age in weeks } \\
\hline Early preterm & $27(26-27)$ & $14(4.0)$ \\
\hline Preterm & $30.5(28-32)$ & $168(48.1)$ \\
\hline Late preterm & $34(33-36)$ & $167(47.9)$ \\
\hline \multicolumn{3}{|l|}{ Growthcategorization at birth } \\
\hline SGA & & $36(10.3)$ \\
\hline AGA & & $313(89.7)$ \\
\hline \multicolumn{3}{|l|}{ Birth weight categories } \\
\hline ELBW & $0.96(0.87-0.99)$ & $18(5.2)$ \\
\hline VLBW & $1.26(1-1.49)$ & $106(30.4)$ \\
\hline LBW & $1.84(1.5-2.8)$ & $225(64.5)$ \\
\hline Length of hospital stay (days) & $14(7-85)$ & \\
\hline \multicolumn{3}{|l|}{ Discharge status } \\
\hline Alive & & $333(95.42)$ \\
\hline \multicolumn{3}{|l|}{ Singleton/Multiple birth } \\
\hline Multiple & & $122(35)$ \\
\hline \multicolumn{3}{|l|}{ Place of birth } \\
\hline In-born & & $187(53.6)$ \\
\hline \multicolumn{3}{|l|}{ Mode of delivery } \\
\hline SVD & & $272(77.9)$ \\
\hline \multicolumn{3}{|l|}{ Maternal Characteristics } \\
\hline \multicolumn{3}{|l|}{ Maternal age category ${ }^{a}$} \\
\hline$\leq 19$ & & $77(22.1)$ \\
\hline $20-24$ & & $114(32.7)$ \\
\hline $25-29$ & & $89(25.5)$ \\
\hline $30-34$ & & $38(10.9)$ \\
\hline$\geq 35$ & & $26(7.4)$ \\
\hline Missing data & & $5(1.4)$ \\
\hline \multicolumn{3}{|l|}{ Parity categories ${ }^{\mathrm{a}}$} \\
\hline Para1 & & $106(30.4)$ \\
\hline Para2 & & $81(23.2)$ \\
\hline Para3 & & $52(14.9)$ \\
\hline Para4 and above & & $109(31.2)$ \\
\hline Missing data & & $1(0.29)$ \\
\hline \multicolumn{3}{|l|}{ Residence $^{a}$} \\
\hline Luwero & & $162(46.4)$ \\
\hline Nakaseke & & $103(29.5)$ \\
\hline Nakasongola & & $61(17.5)$ \\
\hline
\end{tabular}


Table 1 Baseline characteristics of the sample population (Continued)

\begin{tabular}{|c|c|c|}
\hline \multirow[t]{2}{*}{ Baseline Characteristics } & \multirow[t]{2}{*}{$\begin{array}{l}\text { Median (min- } \\
\text { max) }\end{array}$} & \multirow{2}{*}{$\begin{array}{l}\text { Number(N) } \\
\mathrm{n}(\%) \\
N=349\end{array}$} \\
\hline & & \\
\hline Others & & $22(6.3)$ \\
\hline Missing data & & $1(0.28)$ \\
\hline \multicolumn{3}{|c|}{ Maternal HIV seropositivity } \\
\hline Yes & & $29(8.3)$ \\
\hline \multicolumn{3}{|l|}{ Maternal Hypertension } \\
\hline Yes & & $23(6.6)$ \\
\hline \multicolumn{3}{|c|}{ Maternal Diabetes mellitus } \\
\hline Yes & & $1(0.3)$ \\
\hline
\end{tabular}

were not found to be significantly associated with the occurance of PGF (Table 4).

\section{Discussion}

We evaluated the incidence of and factors associated with PGF in hospitalized preterm infants in a neonatal care unit in a rural population in Uganda. We found a very high incidence of PGF- $73 \%$ of the preterm infants were below the 10th percentile for weight at discharge. PGF was not only found in the extremely preterm infants but also in the moderate to late preterms. The findings are consistent with other studies that show that PGF is common in hospitalized preterm infants worldwide. Kumar et al. in a prospective observational study in a level III NICU at a tertiary care teaching hospital in India found the incidence of PGF to be $64.8 \%$ from a study population of 111 preterm infants [4]. Clark et al. reported 28\% PGR among preterm infants who were 23 to 34 weeks in a multi-center study in USA [3]. A more recent study in Korea found postnatal growth failureof 45.9\% from a sample of 2799 VLBW preterms [5]. In Africa, a study done in South Africa also demonstrated early growth failure in a cohort of VLBW preterm infants [11]. The variation in frequency of PGF in these studies can in part be explained by different demographic characteristics, cut offs to define PGF, unit resources and the use of different feeding protocols.

Poor post-natal growth (weight, length or head circumference) is primarily due to inadequate nutritional intake [6]. This early growth deficit affects brain development and has been shown to result in poorer neurodevelopmental outcomes later in life $[7,8]$.
Table 2 Clinical and nutrition characteristics of the preterm infants

\begin{tabular}{|c|c|c|}
\hline Variables & $\begin{array}{l}\text { Median } \\
\text { (min } \\
-\max )\end{array}$ & $\begin{array}{l}\text { Frequency } \\
n(\%)\end{array}$ \\
\hline \multicolumn{3}{|l|}{ Clinical Characteristics } \\
\hline \multicolumn{3}{|l|}{ CPAP } \\
\hline Yes & & $121(34.7)$ \\
\hline CPAP duration (days) median (iqr) & & $4(5)$ \\
\hline \multicolumn{3}{|l|}{ Apnea } \\
\hline Yes & & $29(8.3)$ \\
\hline \multicolumn{3}{|l|}{ Sepsis } \\
\hline Yes & & $47(13.5)$ \\
\hline \multicolumn{3}{|l|}{ NEC } \\
\hline Yes & & $10(2.9)$ \\
\hline \multicolumn{3}{|l|}{ PDA } \\
\hline Yes & & $11(3.2)$ \\
\hline \multicolumn{3}{|l|}{ Requiring $\mathrm{O} 2 \geq 28$ days } \\
\hline Yes & & $6(1.7)$ \\
\hline \multicolumn{3}{|l|}{ Anemia } \\
\hline Yes & & $51(14.6)$ \\
\hline \multicolumn{3}{|l|}{ Route of initial feeds ${ }^{a}$} \\
\hline $\mathrm{BF}$ & & $122(35.0)$ \\
\hline NGT & & $113(32.4)$ \\
\hline Cup & & $110(31.5)$ \\
\hline Missing data & & $4(1.14)$ \\
\hline \multicolumn{3}{|l|}{ Time of initiating enteral feeds ${ }^{a}$} \\
\hline$>48 \mathrm{~h}$ & & $69(19.8)$ \\
\hline$<48 \mathrm{~h}$ & & $277(79.4)$ \\
\hline Missing data & & $3(0.86)$ \\
\hline \multicolumn{3}{|l|}{ Days until initiating enteral feeds } \\
\hline Overall & $1(0-7)$ & \\
\hline$>48 \mathrm{~h}$ & $3(2-7)$ & \\
\hline$<48 h$ & $1(0-2)$ & \\
\hline
\end{tabular}

Feeds intolerance

$$
\text { Yes }
$$

CPAP Continuous positive airway pressure, iqr Interquartile range, NEC Necrotizing enterocolitis, PDA Patent ductus arteriousus, NGT Nasal gastric tube, $N=349^{\circ}$ indicates where we had some missing data

This study showed that delayed initiation of enteral feeds that is after $48 \mathrm{~h}$ of life was 3.7 times more associated with PGF compared to when feeds were started within the first $48 \mathrm{~h}$ of life. A South African study on growth of 92 extremely low birth weight preterm infants at a tertiary hospital also found that being kept nil per os beyond the first day of life was significantly associated with poor growth [12]. Earlier enteral feeding results in earlier achievement of full enteral feeds which 


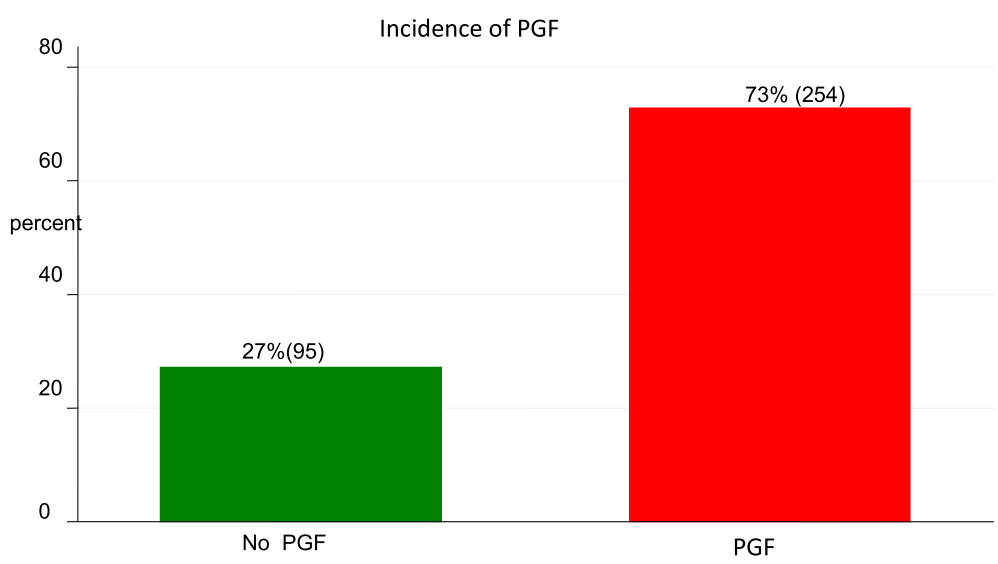

Fig. 1 Bar graph showing the incidence of post-natal growth failure among preterm infants managed at Kiwoko Hospital

means reduced cumulative protein and energy deficits and therefore more weight gain [13]. In low resource settings where parenteral nutrition is not widely used, earlier initiation of enteral feeds may best optimize postnatal nutrition. The WHO also recommends breast feeding within an hour of birth as well as minimal enteral feeds on day one of life for those unable to breastfeed [14].

Although the American Academy of Paediatrics suggests that postnatal growth in preterms should mimic

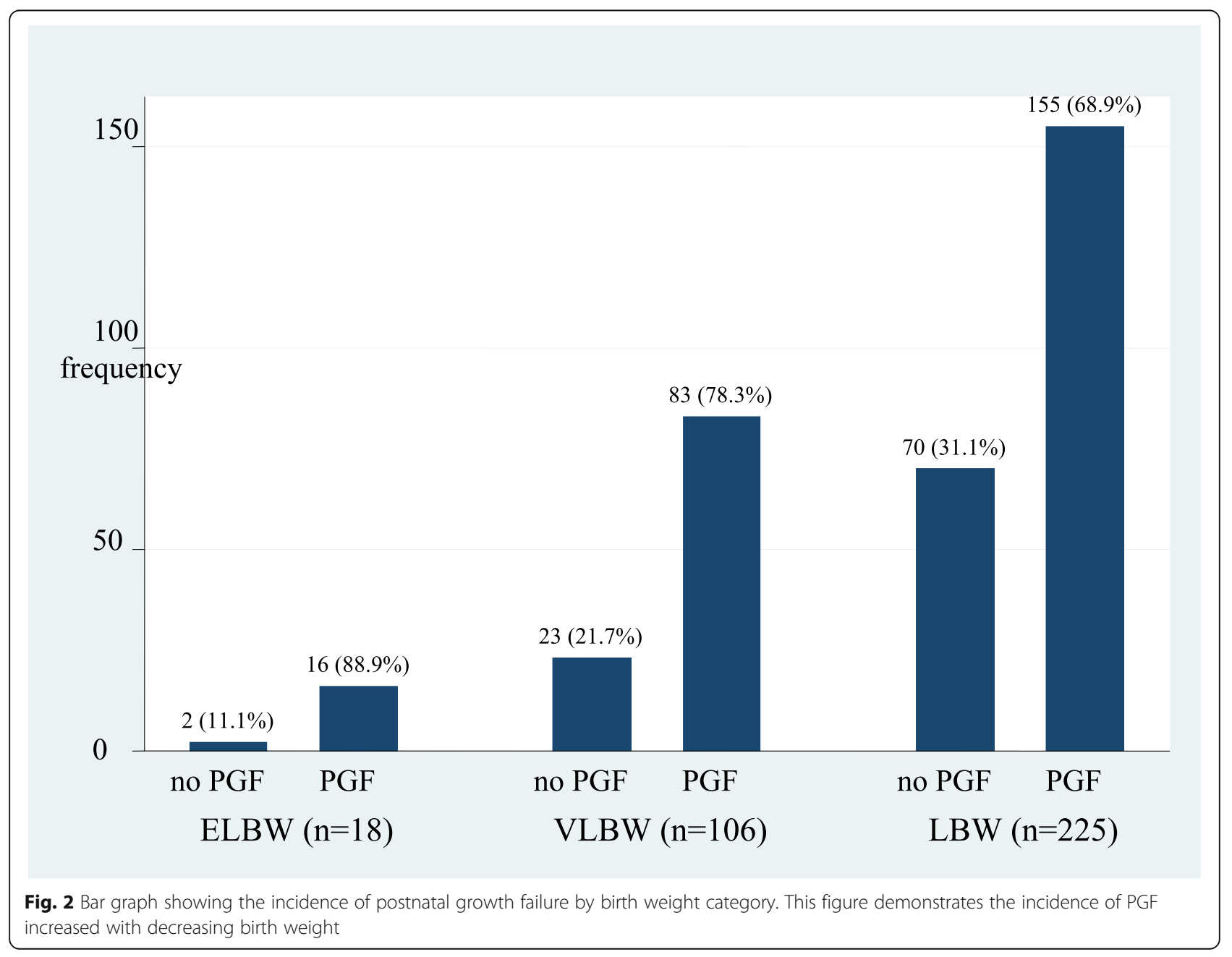


Table 3 Bivariable analysis for factors associated with extrauterine growth restriction among preterm infants managed at Kiwoko Hospital

\begin{tabular}{|c|c|c|}
\hline \multicolumn{3}{|l|}{ Bivariable analysis } \\
\hline Variable & $\mathrm{OR}(95 \% \mathrm{Cl})$ & $p$-value \\
\hline \multicolumn{3}{|l|}{ Sex } \\
\hline Female & 1 & \\
\hline Male & $1.59(0.98,2.57)$ & 0.06 \\
\hline \multicolumn{3}{|c|}{ Gestational age Category } \\
\hline Early preterm & 1 & \\
\hline Preterm & $0.8(0.24,2.66)$ & 0.716 \\
\hline Late preterm & $1.51(0.45,5.1)$ & 0.508 \\
\hline \multicolumn{3}{|c|}{ Length of hospital stay } \\
\hline$<14$ days & 1 & \\
\hline 14 days or more & $1.04(1.02,1.06)$ & $<0.001$ \\
\hline \multicolumn{3}{|l|}{ Birth weight by GA } \\
\hline SGA & 1 & \\
\hline AGA & 0.07 (0.01 0.49) & 0.008 \\
\hline \multicolumn{3}{|c|}{ Singleton/Multiple birth } \\
\hline Singleton & 1 & \\
\hline Multiple & $1.61(0.96,2.71)$ & 0.07 \\
\hline \multicolumn{3}{|l|}{ CPAP } \\
\hline No & 1 & \\
\hline Yes & $2.12(1.24,3.63)$ & 0.006 \\
\hline \multicolumn{3}{|l|}{ Apnea } \\
\hline No & 1 & \\
\hline Yes & $11.65(1.56,86.84)$ & 0.017 \\
\hline \multicolumn{3}{|l|}{ Sepsis } \\
\hline No & 1 & \\
\hline Yes & $4.64(1.62,13.3)$ & 0.004 \\
\hline \multicolumn{3}{|l|}{ Anemia } \\
\hline No & 1 & \\
\hline Yes & $2.22(1,4.91)$ & 0.05 \\
\hline \multicolumn{3}{|c|}{ Time to initiating Oral feeds } \\
\hline$>48 \mathrm{~h}$ & 1 & \\
\hline$<48 \mathrm{~h}$ & $0.29(0.13,0.64)$ & 0.002 \\
\hline \multicolumn{3}{|l|}{ Days to full feeds } \\
\hline$<5$ inclusive & 1 & \\
\hline Above 5 & $1.95(1.17,3.25)$ & 0.01 \\
\hline \multicolumn{3}{|l|}{ Feeds intolerance } \\
\hline No & 1 & \\
\hline Yes & $5.3(1.23,22.79)$ & 0.025 \\
\hline
\end{tabular}

their intrauterine foetal growth rates at the same estimated gestational age, this growth trajectory was not reflected in this study population. Embleton et al. in 2001 related this growth lag to the cumulative energy and protein deficits that occur in the postnatal period [6]. It takes time to initiate as well as maintain adequate nutrient intake in preterm infants and some studies concluded that PGF in preterms is inevitable. Emerging evidence, however, shows that optimizing nutrition can improve post-natal growth in preterms and reduce the incidence of PGF $[15,16]$. A study by Young et al on 124 infants in Korea reported that day 1 parenteral feeding with greater supply of protein and energy decreased the incidence of PGF in VLBW preterms [16]. Another study on 396 preterm infants below 32 weeks gestational age at a university hospital in UK further demonstrated that early postnatal growth failure is not inevitable. The study showed that with early enteral feeding, fortification of human milk as well as employing a multidisciplinary nutrition team in the neonatal unit, infants grew at rates comparable to their intrauterine rates [17].

In this study, preterm infants with sepsis were 6.76 more times likely to have PGF compared to those without sepsis. Being ill increases the basal metabolic requirements and yet the sick preterms are in most cases fed less due to concerns of instability and ability to digest feeds. This creates protein and energy deficits consequently leading to poor growth as has been reported by Bertino et al. 2006 in Italy, Lee et al. 2018 in Korea, and Mabhandi et al. 2019 in South Africa [5, 12, 18].

The incidence of PGF has been shown in some studies to increase as gestational age and birth weight decrease because smaller preterm infants lose more weight and take longer to regain it. Also as gestation age decreases, nutritional requirements increase and achieving satisfactory growth rate become less likely $[3,19]$. In as much as our study was able to demonstrate an increase in the incidence of PGF with decreasing birth weight (Fig. 2), the incidence was highest in moderate to late preterms compared to extremely preterm infants (79\% Vs 71.4\%) at univariate level. Shan et al. [20] and Freitas et al. [21] associated PGF with increasing gestational age which is consistent with our findings. These studies like ours included all preterms less than 37 weeks but earlier studies focused on preterm infants less than 34 weeks and could have missed the growth dynamics in older preterms. At multivariable analysis gestational age was not significantly associated with PGF in this study.

This study had a number of limitations. Given that it was a retrospective chart review, there was missing information from the files that resulted in some patient files being excluded from the study. Weight measurements are subject to errors and some may been incorrectly done leading to misclassification. LNMP was the most commonly used method for estimating gestational age in this population and is less precise than a first trimester ultra sound scan. We were unable to quantify the actual nutrition intake for these preterms using patient files. 
Table 4 Multivariable analysis for factors associated with extrauterine growth restriction among preterm infants managed at Kiwoko Hospital

\begin{tabular}{|c|c|c|c|c|}
\hline Simple Logistic & Crude OR(95\% Cl) & $P$-value & Adjusted OR(95\% Cl) & $P$-value \\
\hline \multicolumn{5}{|l|}{ Sex } \\
\hline \multicolumn{5}{|l|}{ Female } \\
\hline Male & $1.59(0.98,2.57)$ & 0.06 & $1.71(1.01,2.91)$ & 0.043 \\
\hline \multicolumn{5}{|l|}{ Gestation age } \\
\hline Early preterm & 1 & & 1 & \\
\hline Preterm & $0.8(0.24,2.66)$ & 0.716 & $1.7(0.4,7.25)$ & 0.475 \\
\hline Late preterm & $1.51(0.45,5.1)$ & 0.508 & $4.15(0.94,18.43)$ & 0.061 \\
\hline \multicolumn{5}{|l|}{ Birth weight } \\
\hline ELBW & $18(5.2)$ & 0.062 & - & - \\
\hline VLBW & $106(30.4)$ & & - & - \\
\hline LBW & $225(64.5)$ & & - & - \\
\hline \multicolumn{5}{|c|}{ Birth weight for gestation age } \\
\hline SGA & 1 & & 1 & \\
\hline AGA & $0.07(0.01,0.49)$ & 0.008 & $0.12(0.02,0.9)$ & 0.04 \\
\hline \multicolumn{5}{|c|}{ Singleton/Multiple birth } \\
\hline Singleton & 1 & & 1 & \\
\hline Multiple & $1.61(0.96,2.71)$ & 0.07 & $1.81(1.01,3.24)$ & 0.041 \\
\hline \multicolumn{5}{|l|}{ Sepsis } \\
\hline No & 1 & & 1 & \\
\hline Yes & $4.64(1.62,13.3)$ & 0.004 & $6.79(2.15,21.2)$ & 0.001 \\
\hline \multicolumn{5}{|c|}{ Time of initiating Oral feeds } \\
\hline Less than $48 \mathrm{~h}$ & 1 & & 1 & \\
\hline More than $48 \mathrm{~h}$ & $3.44(1.56,7,69)$ & 0.002 & $3.70(1.64,8.33)$ & 0.002 \\
\hline \multicolumn{5}{|l|}{ HIV } \\
\hline No & 1 & & 1 & \\
\hline Yes & $1.88(0.7,5.07)$ & 0.214 & $1.82(0.63,5.26)$ & 0.272 \\
\hline \multicolumn{5}{|l|}{ Hypertension } \\
\hline No & 1 & & 1 & \\
\hline Yes & $2.62(0.76,9.03)$ & 0.127 & $1.67(0.45,6.17)$ & 0.443 \\
\hline
\end{tabular}

The major strength of this study was the good quality data, carefully recorded weights and patient information in a reasonably well organized model neonatal unit in rural Uganda that enabled us to compile this data and report an important topic. To our knowledge, this was the first study in Uganda to investigate PGF among preterm infants.

\section{Conclusion}

Nearly three quarters of preterm infants managed at a rural hospital in Uganda had postnatal growth failure. Initiating enteral feeds after $48 \mathrm{~h}$ of life and sepsis during hospitalization were significantly associated with PGF. Enteral feeds should be initiated as soon as possible in these infants to reduce early protein deficits and hence postnatal growth failure.

\section{Abbreviations}

AGA: Appropriate for gestational age; HIV: Human Immunodeficiency Virus; LBW: Low birth weight; LNMP: Last Normal Menstrual Period; NEC: Necrotizing enterocolitis; NICU: Neonatal Intensive Care Unit; PGF: Postnatal growth failure; SGA: Small for gestation age; VLBW: Very low birth weight; WHO: World Health Organization

\section{Acknowledgements}

We acknowledge Drs. Muhumuza Joshua, David Mukunya and statistician Mukiza Nelson for their great contribution towards this study. We thank Kiwoko Hospital, Adara Development and University of Washington for their contributions to the neonatal database. This study was supported in part by Adara Development.

We also acknowledge Survival Pluss project (no. UGA-13-0030) at Makerere University. Survival Pluss project is funded under NORHED by NORAD; Norway.

\section{Authors' contributions}

CN conceptualized and designed the study, collected data and was involved in data analysis as well as drafted the initial manuscript. RO, VM and FBN supervised the study and were involved in data analysis and interpretation. JN and $\mathrm{ABH}$ approved the use of the patient data set at $\mathrm{KH}$ and were involved in 
manuscript writing. JT and $\mathrm{CH}$ contributed towards drafting the manuscript. All authors read and approved the final version of the manuscript.

\section{Funding}

The study was funded by the Survival Pluss project (no. UGA-13-0030) at Makerere University. Survival Pluss project is funded under The Norwegian Programme for Capacity Development in Higher Education and Research for Development (NORHED) by Norwegian Agency for Development Cooperation (NORAD); Norway.

Adara development also provided some financial support to this study.

\section{Availability of data and materials}

The datasets used and/or analysed during the current study are available from the corresponding author on reasonable request.

\section{Ethics approval and consent to participate}

Consent to carry out this study was sought from:-

1. The Department of Paediatrics and Child heath of Makerere University.

2. School of Medicine Research Ethics Committee- (SOMREC) which approved the study and also gave waiver of obtaining informed consent from the participants given the nature of the study.

3. Kiwoko hospital administration to access records for the period of 1 year (July, 2017 to June 2018).

\section{Consent for publication}

Not applicable.

\section{Competing interests}

The authors declare that they have no competing interests.

\section{Author details}

${ }^{1}$ Department of Pediatrics and Child Health, School of Medicine, Makerere University College of Health Sciences, PO Box 7072, Kampala, Uganda. ${ }^{2}$ Survival Pluss Project, Luwero, Uganda. ${ }^{3}$ Kiwoko Hospital, P0 Box 149, Luwero, Uganda. ${ }^{4}$ University of Washington/Seattle Children's Hospital, Seattle, USA.

Received: 28 August 2019 Accepted: 18 February 2020

Published online: 24 February 2020

\section{References}

1. Unicef, World Health Organization. A decade of tracking progress for maternal, newborn, and child survival: 2015 report. Countdown to 2015. 2015.

2. Fenton TR, Kim JH. A systematic review and meta-analysis to revise the Fenton growth chart for preterm infants. BMC Pediatr. 2013;13:59.

3. Clark $\mathrm{RH}$, Thomas $\mathrm{P}$, Peabody J. Extrauterine growth restriction remains a serious problem in prematurely born neonates. Pediatrics. 2003;111(5):986-90.

4. Kumar M, Tripathi S, Agrawal N, Singh SN. Growth of premature neonates admitted in a level III neonatal unit. Clin Epidemiol Glob Heal. 2014;2(2):56-60.

5. Lee SM, Kim N, Namgung R, Park M, Park K, Jeon J. Prediction of postnatal growth failure among very low birth weight infants. Sci Rep. 2018;8(1):1-8

6. Embleton NE, Pang N, Cooke RJ. Postnatal malnutrition and growth retardation: an inevitable consequence of current recommendations in preterm infants? Pediatrics. 2001;107(2):270-3.

7. Pampanini V, Boiani A, De Marchis C, Giacomozzi C, Navas R, Agostino R, et al. Preterm infants with severe extrauterine growth retardation (EUGR) are at high risk of growth impairment during childhood. Eur J Pediatr. 2015; 174(1):33-41.

8. Sania A, Spiegelman D, Rich-Edwards J, Hertzmark E, Mwiru RS, Kisenge R, et al. The contribution of preterm birth and intrauterine growth restriction to childhood undernutrition in Tanzania. Matern Child Nutr. 2015;11(4):618-30.

9. Fenton TR. Fenton2013Growthchartgirls.Pdf. 2013. Available from: http:// ucalgary.ca/fenton/files/fenton/fenton2013growthchartgirls.pdf

10. Fenton TR. Fenton2013Growthchartboys.Pdf. 2013. Available from: https:// ucalgary.ca/fenton/files/fenton/fenton2013growthchartboys.pdf

11. Mackay CA, Ballot DE, Cooper PA. Growth of a cohort of very low birth weight infants in Johannesburg, South Africa. BMC Pediatr. 2011;11(1):50

12. Mabhandi T, Ramdin T, Ballot DE Growth of extremely low birth weight infants at a tertiary hospital in a middle-income country; 2019. p. 1-9.
13. Nangia S, Bishnoi A, Goel A, Mandal P, Tiwari S, Saili A. Early total enteral feeding in stable very low birth weight infants : a before and after study. J Trop Pediatr. 2018;64(1):24-30.

14. World Health Organization. Guidelines on optimal feeding of low birthweight infants in low and middle-income countries. Geneva: 2011.

15. Clark RH, Wagner CL, Merritt RJ, Bloom BT, Neu J, Young TE, et al. Nutrition in the neonatal intensive care unit: how do we reduce the incidence of Extrauterine growth restriction? J Perinatol. 2003;23:337.

16. Choi AY, Lee $Y W$, Chang M. Modification of nutrition strategy for improvement of postnatal growth in very low birth weight infants. Korean J Pediatr. 2016:59(4):165-73.

17. Andrews ET, Ashton JJ, Pearson F, Beattie RM, Johnson MJ. Early postnatal growth failure in preterm infants is not inevitable; 2018. p. 10-2.

18. Bertino E, Coscia A, Boni L, Rossi C, Martano C, Giuliani F, et al. Weight growth velocity of very low birth weight infants: role of gender, gestational age and major morbidities. Early Hum Dev. 2009;85(6):339-47.

19. Cooke RJ, Ainsworth SB, Fenton AC. Postnatal growth retardation: a universal problem in preterm infants. Arch Dis Child Fetal Neonatal Ed. 2004:89(5):428-30.

20. Shan HM, Cai W, Cao Y, Fang BH, Feng Y. Extrauterine growth retardation in premature infants in Shanghai: a multicenter retrospective review. Eur J Pediatr. 2008:168(9):1055

21. Freitas BA, Priore SE, Lima LM, Franceschini SD. Extrauterine growth restriction: universal problem among premature infants. Rev Nutr. 2016;29:53-64.

\section{Publisher's Note}

Springer Nature remains neutral with regard to jurisdictional claims in published maps and institutional affiliations.
Ready to submit your research? Choose BMC and benefit from:

- fast, convenient online submission

- thorough peer review by experienced researchers in your field

- rapid publication on acceptance

- support for research data, including large and complex data types

- gold Open Access which fosters wider collaboration and increased citations

- maximum visibility for your research: over $100 \mathrm{M}$ website views per year

At BMC, research is always in progress.

Learn more biomedcentral.com/submissions 